\title{
Effect of Pin Size on Reciprocating Sliding Wear Test of Ti-6Al-4V
}

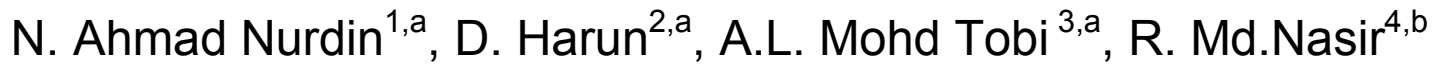 \\ ${ }^{a}$ Faculty of Mechanical and Manufacturing Engineering, \\ Universiti Tun Hussein Onn Malaysia, Batu Pahat, Malaysia. \\ bUSM School of Mechanical Engineering, Universiti Sains Malaysia (Engineering Campus) \\ Seri Ampangan 14300 Nibong Tebal Seberang Perai Selatan, Pulau Pinang, Malaysia \\ 1hd130001@siswa.uthm.edu.my, 2dalila@uthm.edu.my, ${ }^{3}$ abdlatif@uthm.edu.my, \\ ${ }^{4}$ meramdziah@eng.usm.my
}

Keywords: Plasticity, reciprocating sliding wear test, pin size

\begin{abstract}
Ti-6Al-4V is material that has the special characterisation and widely used in tribology studies. In this study reciprocating sliding test between Ti-6Al-4V pin on Ti-6Al-4V flat surface was conclude and focussed on the different contact area of pin size. The testing is run using tribometer pin-on-flat machine where the parameter set on the computer. The sample profilometry than analysed using 3D optical microscope $(\mathrm{OM})$ and value of hardness get from Vickers hardness (HV) test. The contact pressure for $6.5 \mathrm{~mm}$ is higher than the $12 \mathrm{~mm}$ pin size, that brings the higher depth of wear.
\end{abstract}

\section{Introduction}

Titinium Alloy (Ti-6Al-4V) is extensively applied in mechanical industries, especially in aeronautics, automotive as well as biomedical [1]. The combination of high mechanical properties of Ti-6Al-4V such as low density, excellent corrosion resistance makes it valuable and high cost material. In tribology study, the properties limitation makes this material extension to common applications [2].

The reciprocating sliding phenomenon is widely discussed in tribology which consist the three ideas where there are wear, friction, and lubrication [3]. Reciprocating sliding occur when two or more contacting surface area moving on each other. Sliding is usually experienced on mechanical part where the friction of the sliding may reduce their service life [4]. In order to predict the life of components, the profilometry of wear scars width and depth, is valuable information in designing mechanical components [5].

Reciprocating sliding involving the contact movement where it produced the energy. The larger the contact dimension, the lower the energy wear rate [6]. The contact study on the tribology contributes to a more detail analysis in quantitative as well as qualitative [7]. By consider the experimental results of two surfaces that placed into contact under normal load, the apparent area of contact is not similar as real as contact area, where the real contact should be much less than the area of apparent contact [8]. The contact is the important sub topic that have discussed in tribology field. The area of contact always inferred by researchers from the contact mechanics of excellent measurement methods [9]. In this paper the effect of pin size on the wear behavior of reciprocating sliding wear test has been investigated in terms of hardness value, coefficient of friction, and wears scar details.

\section{Experimental Method}

Specimen preparation

Ti-6Al-4V alloy is the most widely used titanium alloy of the alpha-plus-beta class, and is also the most common of all titanium alloys. Ti-6Al-4V is the material that investigated in this study. The 
special characteristic of this material is the main factor for the selection. The element composition in the Ti-6Al-4V is calculated in percent maximum unless given as a range in Table 1

Table 1: The element composition in the Ti-6Al-4V

\begin{tabular}{|c|c|c|c|c|c|c|c|c|c|}
\hline Elements & $\mathrm{N}$ & $\mathrm{C}$ & $\mathrm{H}$ & $\mathrm{Fe}$ & $\mathrm{O}$ & $\mathrm{Al}$ & $\mathrm{V}$ & $\mathrm{Y}$ & $\mathrm{Ti}$ \\
\hline Weight\% & 0.05 & 0.08 & 0.125 & 0.4 & 0.2 & $\begin{array}{c}5.5- \\
6.75\end{array}$ & $3.5-4.5$ & 0.005 & Balance \\
\hline
\end{tabular}

Ti-6Al-4V specimens came in cylindrical rod and flat bar. The upper specimen, cylindrical rod of $25 \mathrm{~mm}$ length with one edge of the cylindrical rod is rounded to form a hemispherical cap with radius of curvature $\emptyset 6.5 \times 25 \mathrm{~mm}$ and $\emptyset 12 \times 25 \mathrm{~mm}$ and the flat specimens made of rectangular blocks with dimension $100 \times 25 \times 8 \mathrm{~mm}$. Table 2 shows the test parameter that has been used in this study.

Table 2: Testing parameters

\begin{tabular}{|l|l|}
\hline Normal load, $P(\mathrm{~N})$ & 200 \\
\hline Duration, $\mathrm{s}$ & 4200 \\
\hline Speed, RPM & 100 \\
\hline Diameter pin size, $\mathrm{mm}$ & $6.5,12$ \\
\hline
\end{tabular}

Reciprocating sliding wear test

The tribometer pin-on-flat machine is used to run the experiment in dry condition at ambient air shows in Fig. 1. It is manufactured by Ducom Triboinnovaters. The experiment set up with different pin size $6.5 \mathrm{~mm}$ and $12.0 \mathrm{~mm}$, duration of time at $4200 \mathrm{~s}$, speed of motor 100 RPM and normal load $200 \mathrm{~N}$. The pin is placed in the upper specimen holder meanwhile the flat specimen is placed in the lower specimen holder. Both specimens are clamped and the normal load is applied to the upper specimen. The upper specimen will move in reciprocating sliding manner on the flat surface which remain static until the end of testing.

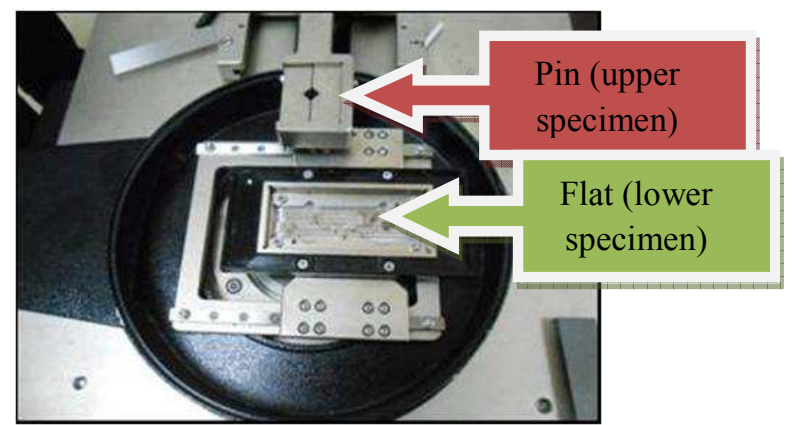

Fig. 1: Flat and pin specimen are placed

\section{Microstructure characterization}

Specimens are cleaned properly using chemical liquid ethanol to ensure freedom from any dust. After the testing, profilometry of wear track width, depth, and area is evaluated using 3D optical microscope. Micro Vicker's hardness-tester is used to determine the hardness of the wear region. The load is set at $980.7 \mathrm{mN}$ (HV0.1) and indented to the surface for $5 \mathrm{~s}$ at are unworn, worn and black spot surface areas. Black spot in this study is known as the accumulated debris on the worn surface of the track and it especially collected at the end of wear track. 


\section{Results and Discussions}

\section{Coefficient of friction}

Fig. 2 shows the plots of the coefficient of friction as a function of different pin. The COF suddenly jump at maximum value at 0.314 after about $1 \mathrm{~s}$ for pin $6.5 \mathrm{~mm}$. The average COF for the reciprocating sliding results is 0.265 and it remains stable until the end of testing. Finding by Johnson K. L., shows that in excess of 0.25 coefficient of friction with the presence of plastic deformation on the wear surface [10].
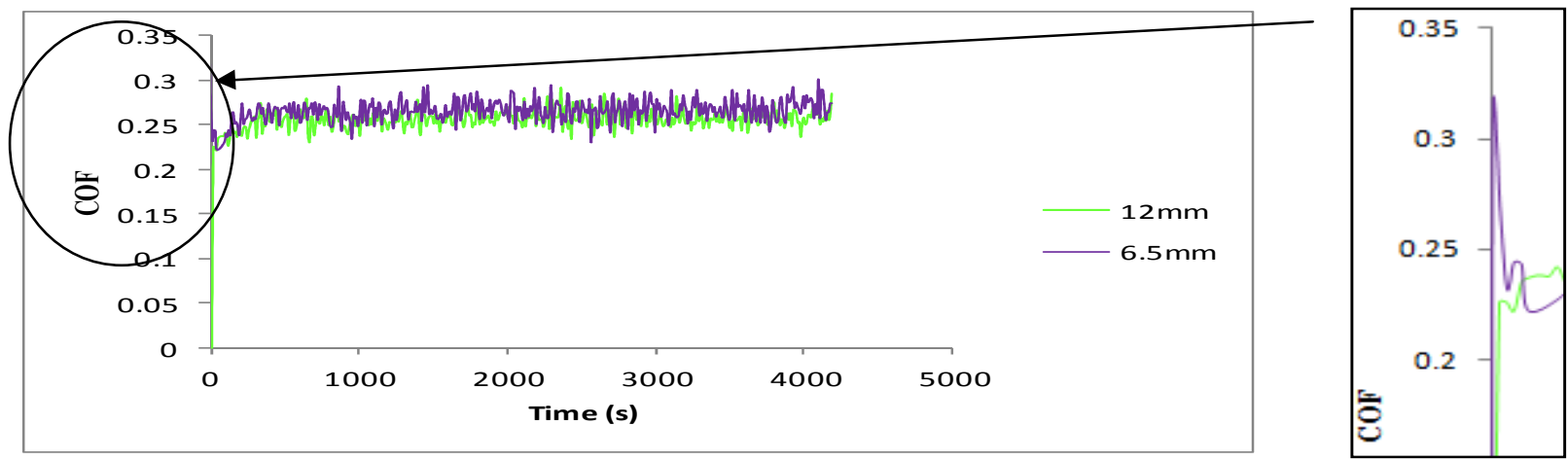

Fig. 2: Evolution of COF for different pin size

\section{Wear scar details}

Fig. 3 shows wear track profile for pin size $12 \mathrm{~mm}$ sliding at the end of $4200 \mathrm{~s}$. Fig. 3(a) shows the wear sliding direction and scar width image. The width of worn surface was measured from point a to point $b$. This dry reciprocating sliding test produced "U"-shaped (scar with single valley) at the center of the track shows in Fig. 3 (b). The wear depth results below the reference line (material removal) and above the reference line is the adhesion phenomena. The profilometry results within the test are similar to fretting test conducted by Paulin C. [11].

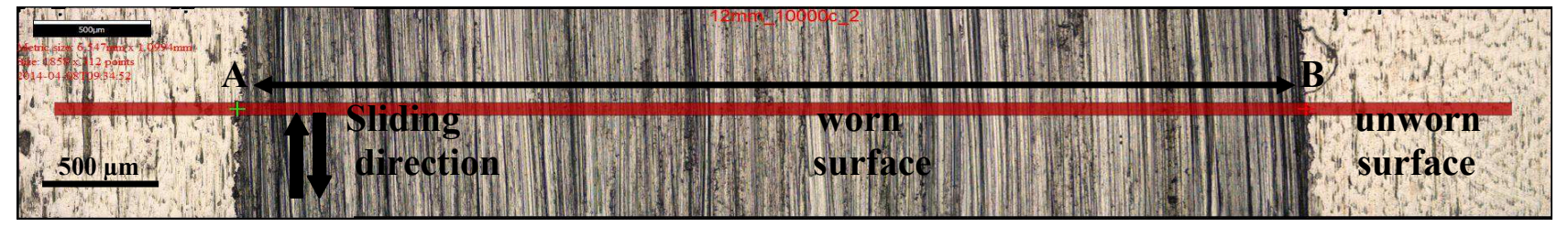

(a)

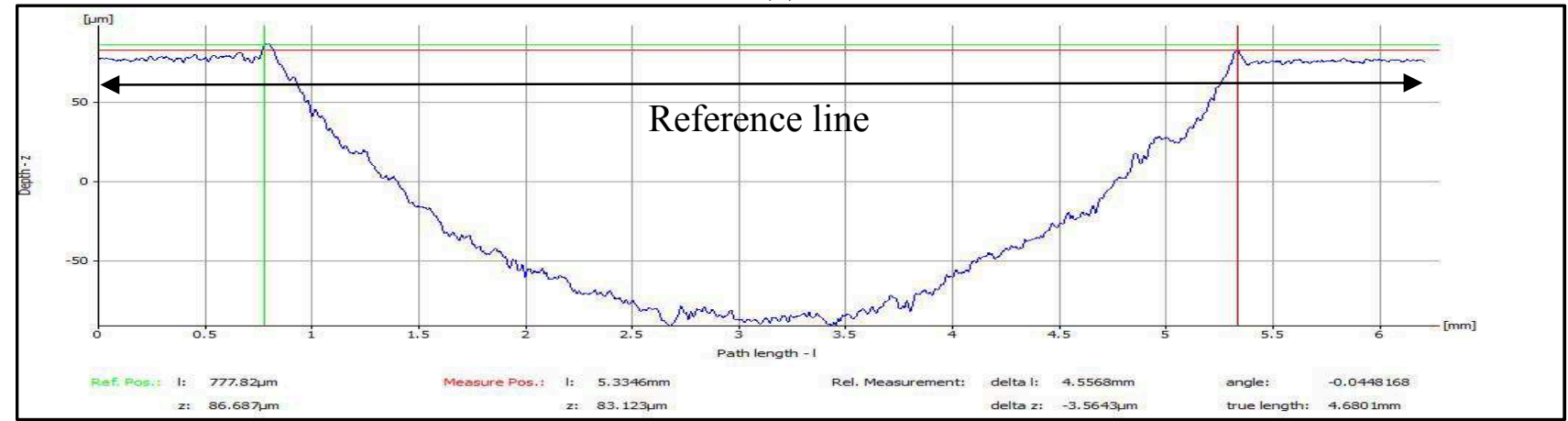

(b)

Fig. 3: Wear track profile $(\mu \mathrm{m})$ for pin size $12 \mathrm{~mm}$ sliding until 4200 seconds (a) the center wear track sliding image (b) The profilometry of the wear scar and depth at center track Fig. 4 (a) shows the wear depth against duration of cycles for different contact area which is $6.5 \mathrm{~mm}$ and $12 \mathrm{~mm}$ pin size. The lower contact area brings the higher wear depth than higher contact pressure. Meanwhile, in Fig. 4 (b) shows the wear width of $12 \mathrm{~mm}$ is higher than $6.5 \mathrm{~mm}$. 


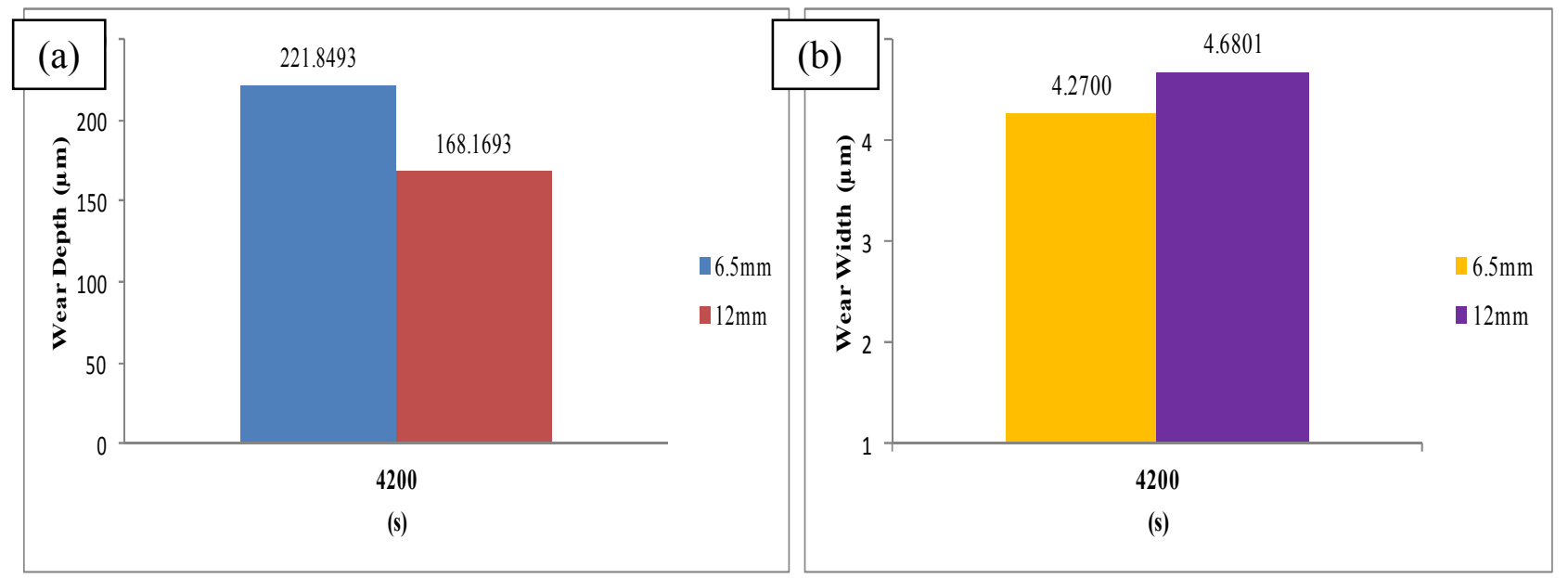

Fig. 4: Graph of (a) wear depth $(\mu \mathrm{m})$, (b) wear width $(\mu \mathrm{m})$ versus duration of cycles (s) for different pin size $(\mathrm{mm})$

Fig. 5 shows the black spot area of the wear scar for $12 \mathrm{~mm}$ pin size. The same figures of black spot also determine for $6.5 \mathrm{~mm}$ pin size. The black spot is figuring out mostly at the end of the wear track specimen and also a few on the sliding wear track. The black spot mention as collected wear debris on the top layer surface that mostly accumulated at the edge and a few at worn track of the test at different sliding loads [12]. Fig. 6 shows the results of hardness test. For the Vicker's Hardness, HV test, it shows that the unworn and worn area is slightly different between the contact size and increase slightly from unworn to worn. The black spot shows the dramatically change of $\mathrm{HV}$ values, especially on $12 \mathrm{~mm}$ pin size. This reproducibility the wear mechanism for these two different pin size are different because of the black spot area [13].

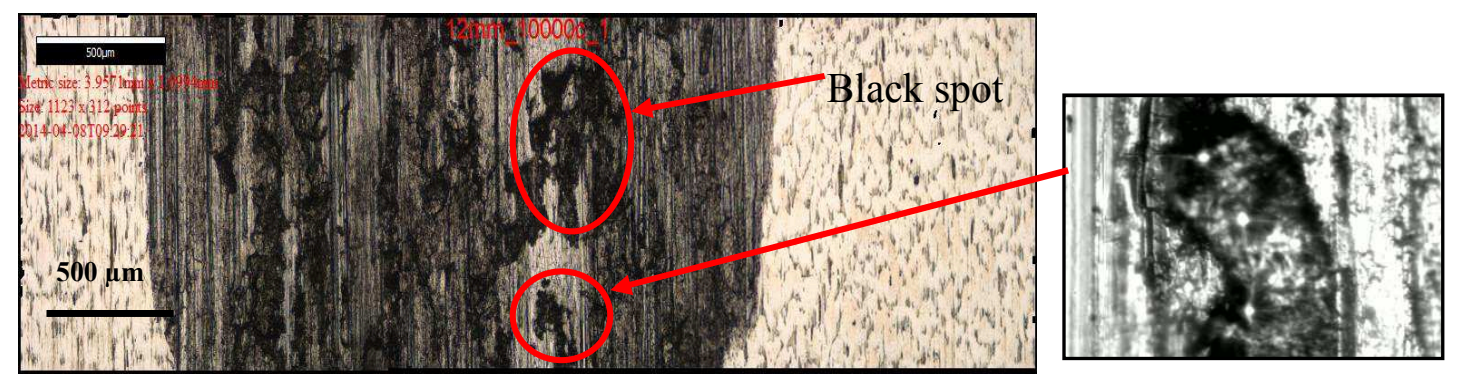

Fig. 5: Black spot area of hardness test for $4200 \mathrm{~s}$ duration of cycles for $12 \mathrm{~mm}$ pin size

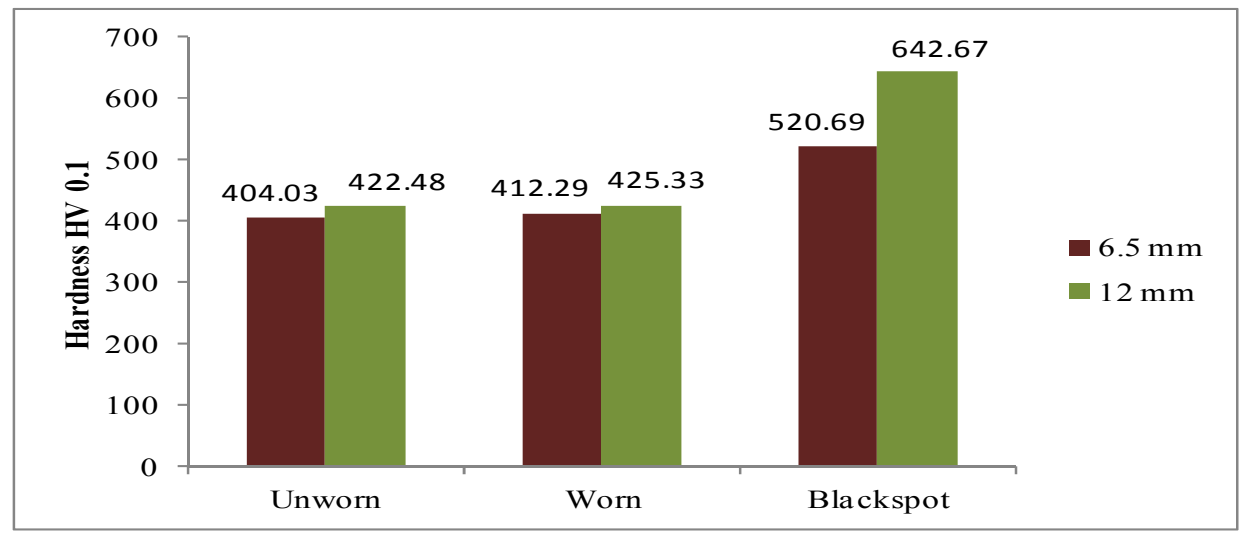

Fig. 6: Comparison results of hardness (HV) test for unworn, worn, and blackspot 


\section{Conclusions}

The reciprocating sliding wear of $\mathrm{Ti}-6 \mathrm{Al}-4 \mathrm{~V} / \mathrm{Ti}-6 \mathrm{Al}-4 \mathrm{~V}$ contact was studied under constant normal load, speed of the motor, and duration of cycles with variable contact area (pin size) conditions.

The friction behavior of the $\mathrm{Ti}-6 \mathrm{Al}-4 \mathrm{~V} / \mathrm{Ti}-6 \mathrm{Al}-4 \mathrm{~V}$ condition is constant between 0.25 and 0.3 , it appears to be independent of pressure, contact size and sliding distance. The lower contact of area brings the higher contact of pressure. The higher contact pressure was shown the increased contact depth. Hardness test shows that the mechanism for wear scar is changed by the developers of the black spot.

\section{Acknowledgement}

The authors acknowledge the financial support by the Universiti Tun Hussein Onn Malaysia (Research Acculturation Grant Scheme No. R011).

\section{References}

[1] Ghazali M.J., Rainforth W.M. Jones H., Dry sliding wear behaviour of some wrought, rapidly solidified powder metallurgy aluminium alloys. Wear, 259(1-6), (2005) 490-500.

[2] Fouvry S., Duó P., Perruchaut Ph., A quantitative approach of Ti-6Al-4V fretting damage: friction, wear and crack nucleation. Wear, 257 (9-10), (2004) 916-929.

[3] Ghazali M.J., Rainforth W.M., Jones H., The wear of wrought aluminium alloys under dry sliding conditions. Tribology International, 40(2), (2007) 160-169.

[4] Mohd Tobi A.L., Shipway P.H., Leen S.B., Gross slip fretting wear performance of a layered thin W-DLC coating: Damage mechanisms and life modeling. Wear, (271) 9-10, (2011) 15721584.

[5] Stachowiak G. W., \& Batchelor A.W., Engineering Tribology, Elsevier ButterworthHeinemann, Oxford Uk (2013).

[6] Fouvry S., Paulin C., Deyber S., Impact of contact size and complex gross-partial slip conditions on Ti-6Al-4V/Ti-6Al-4V fretting wear. Tribology, 42 (3), (2009) 461-474.

[7] Ding J., Leen S.B., McColl I.R., The effect of slip regime on fretting wear-induced stress evolution. International Journal of Fatigue, (26) 5, (2004) 521-531.

[8] Mulvihill D.M., Kartal M.E., Nowell D., Hills D.A., An elastic-plastic asperity interaction model for sliding friction. Tribology international, 44 (12), (2011) 1679-1694.

[9] Kenneth C Ludema, Friction, wear, lubrication. A text book in tribology. (2000) 59 - 60

[10] Johnson K. L., Contact mechanics and the wear of metals. Wear, 190, (1995) 162-170.

[11] Paulin C., Fouvry S., Deyber S., Wear kinetics of Ti-6Al-4V under constant and variable fretting sliding conditions. Wear, (259) 1-6, (2005) 292-299.

[12] Kenneth C Ludema, Friction, wear and lubrication. A text book in tribology. (2000) $79 \& 131$.

[13] Everitta N.M., Dinga J., Bandaka G., Shipwaya P.H., Leenb S.B., Williamsa E.J, Characterisation of fretting-induced wear debris for Ti-6Al-4 V. Wear, 267 (1-4), (2009) 283291. 